\title{
Em Torno da Não-Recepção de John Keats no Portugal de Oitocentos'
}

Miguel Dias

Mestre em Tradução

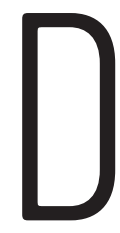

esde meados do século XIX que John Keats (1795-1821) foi apontado como um autor canónico na Literatura Inglesa, particularmente no âmbito dos estudos sobre o Romantismo, não obstante a sua fraca recepção crítica na Inglaterra de inícios de Oitocentos. Juntamente com Lord Byron (17881824) e com Percy Bysshe Shelley (1792-1822), Keats foi enquadrado na chamada segunda geração de poetas românticos ingleses. A sua poesia, particularmente a escrita entre 1819 e 1821, considerado como o seu período de maturação poética, encontra-se presentemente entre a mais analisada e interpretada no âmbito da Literatura Inglesa. O poeta será talvez mais conhecido pelas suas odes, embora a sua correspondência com família e amigos também tenha vindo a ser bastante apreciada entre o público leitor e entre estudiosos.

Em Portugal, é possível encontrar-se presentemente algumas traduções do poeta, assim como recensões críticas sobre a sua obra e influência em determinados autores portugueses do século XX. A recepção de Keats no país foi, contudo, um processo demorado e tardio. De facto, até 1960 apenas existiam duas traduções portuguesas da sua poesia (uma delas classificada pelo próprio tradutor como uma imitação, e a outra consistindo numa brevíssima tradução de

1. O presente artigo resulta de uma versão de parte da Dissertação de Mestrado em Tradução (Área de Especialização em Inglês), intitulada Sobre a (Não-) Tradução de John Keats: Séculos XIX-XX, realizada sob a orientação da Prof. ${ }^{a}$ Doutora Gabriela Gândara Terenas e a co-orientação da Prof. ${ }^{a}$ Doutora Maria Zulmira Castanheira e defendida em provas públicas em Novembro de 2017. Cf. Dias, 2017. 
uma quadra, sem qualquer referência ao título do poema original) e dois ensaios críticos sobre a sua obra. Embora o poeta tenha sido alvo de elogios por parte de autores como Eça de Queirós ou Fernando Pessoa, a sua recepção em Portugal até meados do século XX foi praticamente nula.

Será importante referir que o caso de John Keats não é único - a vasta maioria daqueles considerados hoje como os principais poetas românticos ingleses não chegou a ser traduzida em Portugal durante o século XIX, período áureo do Romantismo. No tocante à imprensa periódica, grande responsável pela introdução e difusão de literatura estrangeira e de novos autores entre a população leitora, verifica-se que os jornais e as revistas do Romantismo se interessavam "por poetas menores, ao mesmo tempo que ignoravam os grandes líricos ingleses seus contemporâneos". (Castanheira, 2008: 161) Assim, poetas como Thomas Moore (1779-1852) e Thomas Campbell (17771844), que não se instituíram como figuras canónicas no panorama romântico inglês, receberam uma maior atenção em Portugal do que figuras-chave como o visionário William Blake (1757-1827), os Lake Poets Samuel Taylor Coleridge (1772-1834) e William Wordsworth (1770-1850), e o politicamente radical Percy Bysshe Shelley. De facto, Blake, Coleridge e Wordsworth apenas viriam a ser traduzidos em Portugal no século seguinte, não tendo atingindo uma recepção literária significativa no país até então.

De entre os seus conterrâneos da segunda geração romântica inglesa, John Keats foi o que, ao todo, menos traduções e referências viu surgir em Portugal. O caso de Lord Byron foi porventura o mais manifesto dos três. Difundido em Portugal desde a primeira metade do século XIX, inicialmente através de traduções francesas, o poeta foi sendo cada vez mais traduzido para português e reconhecido por grandes nomes da literatura romântica portuguesa, como Almeida Garrett, Alexandre Herculano e Camilo Castelo Branco, entre outros. Já Shelley, muito à semelhança de Keats, foi profundamente subvalorizado em Portugal durante o século XIX, contando apenas com uma tradução portuguesa conhecida: a ode "Mont Blanc", que, em 1895, foi traduzida no periódico lisboeta A Leitura, por um autor anónimo.

Torna-se curioso verificar as razões que levaram a uma recepção tardia de românticos como Keats e Shelley, especialmente quando comparados a outras figuras dos Romantismos anglo-saxónicos, 
como Lord Byron e Sir Walter Scott (1771-1832), que, desde os inícios do século XIX, foram amplamente apreciados em Portugal.

A disseminação de poesia traduzida para português, sem dúvida uma das formas mais directas de recepção literária de autores estrangeiros no país, ${ }^{2}$ constituiu um fenómeno que atingiu um auge sem precedentes durante o século XIX. Inúmeras traduções poéticas despontaram ao longo deste século, acompanhando uma popularização generalizada da actividade tradutória, publicada tanto em volumes como sob a forma de poemas soltos, dispersos entre os vários jornais e revistas de cariz literário que caracterizavam a imprensa periódica portuguesa. Nas palavras de Jorge Bastos da Silva,

\begin{abstract}
A tradução das línguas europeias modernas ganha grande relevo com a abertura do País ao exterior trazida pela instauração do regime liberal. (...) Neste panorama, é óbvio que surgem novas necessidades e oportunidades de traduzir. Traduz-se para os negociantes, para a imprensa, para os editores, para o teatro. Traduz-se literatura, notícias, documentos legais, correspondência. Na verdade, é muito de traduções que se alimenta a vida cultural portuguesa desta época, traduções em que tanto se encontram empenhados figuras de primeiro plano na sociedade e nas Letras como homens obscuros, assoldadados (...). (2014: 12)
\end{abstract}

Para o presente estudo de caso, o fenómeno mais relevante será a tradução de poesia inglesa, que, embora não tenha usufruído da mesma divulgação e apreciação que a poesia francesa, ainda assim serviu de fonte de inspiração para vários tradutores portugueses oitocentistas, mesmo que nem sempre fosse directamente vertida directamente de um original inglês. Segundo o levantamento de Isabel Maria da Cruz Lousada, Para o Estabelecimento de uma Bibliografia Britânica em Português (1554-1900) (1998), nesta época destacou-se o número de traduções dos poetas Lord Byron, Thomas Gray (17161771), James Macpherson (1736-1796) (mais conhecido entre o público leitor como Ossian, por ser o alegado tradutor deste bardo gaélico) e Edward Young (1683-1765), sendo que, deste conjunto, apenas Byron produziu poesia durante esse século.

2. Cf. Machado e Pageaux, 1988: 86. 
No tocante à poesia, nenhum autor romântico inglês atingiu o nível de difusão de Byron no sistema literário português oitocentista. Tornado famoso tanto pela qualidade da sua obra literária como pela sua personalidade singular, este foi o poeta romântico inglês que maior impacte alcançou na Europa. Inicialmente lido em Portugal através das traduções francesas de Benjamin de la Roche e de Amédée Pichot, ${ }^{3}$ o poeta rapidamente atingiu uma intensa recepção em terras lusitanas, tal como Gabriela Gândara Terenas amplamente demonstra. ${ }^{4}$ Devido a determinadas estâncias do Canto I do seu poema narrativo Childe Harold's Pilgrimage (1812-18), onde Childe Harold, o protagonista largamente inspirado nas experiências pessoais do escritor durante as viagens pela Europa entre 1809 e 1811, descreve de forma pouco amistosa a cidade de Lisboa e o povo português no geral (embora as estrofes seguintes sejam de apreço por Sintra e pela sua beleza natural), os portugueses estabeleceram uma autêntica relação de amor-ódio com o poeta. Pode dizer-se que o episódio no qual Childe Harold se queixa, entre outras coisas, da sujidade (seja ela literal ou metafórica) de Lisboa e dos seus habitantes, bem como do facto de os portugueses não saberem apreciar as belezas de Sintra, foi analisado até à exaustão, gerando um largo número de artigos e algumas obras dedicadas à estada de dez dias de Byron em Portugal e a estas dezanove estrofes (da XIV à XXXIII) específicas de Childe Harold's Pilgrimage. É claro que esta passagem de Byron por Portugal, assim como os versos dedicados ao país, contribuíram enormemente para o seu portentoso reconhecimento literário. Embora sentimentalmente ferido, o povo português reconheceu rapidamente o seu génio artístico, e inúmeras traduções das suas obras e poemas foram completadas ao longo do século XIX, tanto vertidas do francês como do inglês, sendo a primeira datada de $1833 .{ }^{5}$ Apesar de terem também sido editadas em volume (publicados principalmente no início e final do século), as traduções de Byron surgiram maioritariamente através de contribuições presentes nos vários periódicos literários da época, que difundiam igualmente

3. Cf. Flor, 2009: 147.

4. Cf. Terenas, 2004, Vol. II: 891-916.

5. Cf. Sousa, 2004: 164 e176. 
dados biográficos e críticas à poesia deste romântico. ${ }^{6}$ Segundo Maria Leonor Machado de Sousa, a enorme fama que Byron atingiu em Portugal foi, em grande parte, devida ao seu carácter pessoal e à sua personalidade peculiar, cujas características transpareceram muitas vezes nas suas personagens, eventualmente culminando no chamado "herói byroniano": "Whatever Byron's influence in Portugal, his contempt for society and his defying of the world, a trait which has been called Titanism and even Satanism, was the principal reason which made him a hero-poet and a symbol". (2004: 174)

Sir Walter Scott foi o único autor romântico anglo-saxónico que se equiparou a Byron no tocante a traduções portuguesas realizadas ao longo do século XIX. Inicialmente introduzido em Portugal em 1830, através das traduções francesas de Auguste Defauconpret dos seus romances históricos, ${ }^{7}$ Scott apenas foi traduzido directamente do inglês a partir de 1835. Poucos anos depois começariam a surgir as famosas traduções, feitas a partir do inglês, de André Joaquim Ramalho e Sousa (1790-1857), que obtiveram uma recepção bastante positiva na imprensa periódica a partir de 1838. Traduções do original inglês e traduções via mediação francesa começaram então a coexistir no sistema literário português, sendo que o autor rapidamente se consagrou como um dos escritores de língua inglesa mais conhecidos no Portugal oitocentista. A sua poesia também foi recebida e traduzida no país, tanto em volume como em curtas traduções publicadas em periódicos, embora não tenha alcançado a mesma propagação do que os seus romances históricos. ${ }^{8}$ Maria Laura Bettencourt Pires, cuja obra estuda a recepção de Walter Scott em Portugal, procura explicar esta voga do autor escocês através de quatro características distintas presentes na imagem do autor e na sua produção literária: a sua "fama de escritor moralista" entre o público leitor; a existência nas suas obras de "várias personagens populares cujos costumes, indumentária e linguagem dialectal eram relatados"; "um certo equilíbrio e didactismo clássico" que facilitaria a sua introdução numa literatura portuguesa ainda não completamente entregue aos valores românticos; assim como "as

\footnotetext{
6. Cf. Castanheira, 2008: 164 .

7. Cf. Braga, 2014: 46.

8. Cf. Terenas, 2004, Vol. II: 891-916; e Castanheira, 2008: 151.
} 
evocações do passado e descrição de modos de vida antigos [que] estavam de acordo com o nosso saudosismo pela glória perdida". (1979: 38-39)

Não obstante, é inegável o importantíssimo papel desempenhado pela mediação francesa na transposição e recepção destes e de outros autores estrangeiros em Portugal. Através de tal mediação, Portugal teve acesso a obras escritas em distintas línguas, particularmente as de origem anglo-germânica, cujo domínio seria muito mais comum no âmbito do centro cultural do Ocidente que era a França de inícios do século XIX. Após uma análise do sistema literário francês, torna-se evidente que os autores ingleses que maior reconhecimento alcançaram no país foram os mesmos que se tornariam os mais traduzidos e lidos em Portugal. A imprensa periódica nacional foi um espelho dessa realidade, ${ }^{9}$ evidenciando que a disseminação literária e a imprensa periódica andavam quase sempre de mãos dadas. Através dos numerosos jornais e revistas oitocentistas de cariz predominantemente cultural, mas onde a componente literária geralmente prevalecia ${ }_{1}^{10}$ chegavam traduções de inúmeros autores e obras que, até então, não haviam sido apreciados no nosso país. Segundo Maria Zulmira Castanheira, esta acção mediadora evidenciou-se em força em textos provenientes da Grã-Bretanha, frequentemente traduções de traduções publicadas em periódicos gauleses:

Com efeito, deparámos nas páginas dos jornais e revistas [portugueses do Romantismo] com muitas traduções de obras inglesas feitas a partir de traduções e versões francesas, e também com traduções de textos crítico-valorativos de proveniência francesa, o que significa que o conhecimento e [sic] apreciação da literatura britânica entre nós, no período em causa, dependeram em larga medida da França e foram, portanto, condicionados pela forma como este país leu, seleccionou, traduziu e criticou a produção literária do outro lado da Mancha. (2008: 130)

9. Esta temática foi aprofundada por Gabriela Gândara Terenas, em Diagnoses Especulares: Imagens da Grã-Bretanha na Imprensa Periódica Portuguesa (1865-1890) (2004) e, depois, por Maria Zulmira Castanheira, em A Grã-Bretanha na Imprensa Periódica de Romantismo Português: Imagens Polimórficas (2005).

10. Cf. Castanheira, 2008: 130. 
Assim, por um lado, essa mediação proporcionou acesso a textos em línguas que não eram inteiramente dominadas pelo público leitor português (como era frequentemente o caso do inglês); ${ }^{11}$ por outro lado, condicionou a oferta ao que seria considerado o gosto da cultura francesa e o que esse sistema "seleccionou, assimilou e transferiu", para usar as palavras de João Almeida Flor. (1997: 510)

Tal mediação, exercida através de uma imprensa escrita detentora de uma posição privilegiada enquanto principal meio de comunicação social, possuía a capacidade de condicionar e influenciar a percepção dos leitores consoante a selecção de temas e a importância e/ou hierarquização atribuída aos mesmos. ${ }^{12}$ Tal como Gabriela Gândara Terenas refere em "French Mediation, the Construction of British Images and the Portuguese Press", essa mediação estendia-se para além dos textos literários, conduzindo à própria formação de uma imagem cultural da Grã-Bretanha através do olhar francês. Para a autora, esta tendência oitocentista de mediar aspectos culturais e textos de origem britânica através de fontes francesas deveu-se, fundamentalmente, ao pleno conhecimento da língua francesa entre os intelectuais e jornalistas portugueses da época, à regular circulação de obras e periódicos franceses e ao lugar central ocupado pela França na esfera do polissistema europeu, em contraponto com o estatuto periférico de Portugal. (2009: 161) ${ }^{13}$ Tornou-se, assim, mais comum a divulgação de uma imagem cultural britânica construída não a partir de um conhecimento directo da Grã-Bretanha, mas mediada pelo sistema cultural francês, representada nos periódicos de origem maioritariamente parisiense. Assim, um articulista português responsável por traduzir do francês um texto de origem britânica, ou sobre a Grã-Bretanha, deparar-se-ia directamente com um juízo de valor e determinadas escolhas feitas previamente por um

11. Ibidem

12. Cf. Terenas, 2004, Vol. I: 26-27.

13. Recorde-se que, segundo a teoria dos polissistemas, proposta por Itamar Even-Zohar em 1969 e 1970, e estabelecida em 1990 no vol. 11, ed. 1, de Poetics Today, a disseminação de uma determinada literatura fora do seu país natal consiste num reflexo da predominância desse país face aos demais. Em grande medida, Portugal foi um produto da centralidade político-cultural da França, um grande sistema dominante na Europa, enquanto Portugal ocupava uma posição periférica e, portanto, de menor importância e influência, tanto cultural como literária. A Inglaterra viria também a consagrar-se como um sistema central, embora a influência francesa durante o século XIX fosse inegável. 
receptor e emissor de um contexto cultural diferente do seu. (40-41) Transpareceu, assim, em Portugal, uma imagem do Outro (britânico) incubada, em grande parte, na França.

No âmbito da recepção de autores estrangeiros em Portugal, John Keats poderá ser agrupado com grande parte dos poetas românticos ingleses, uma vez que a sua recepção no sistema literário português de Oitocentos se revelou incrivelmente desoladora e limitada. Segundo as obras de referência de A.A. Gonçalves Rodrigues ${ }^{14}$ e de Isabel Maria da Cruz Lousada ${ }^{15}$ não existem quaisquer registos de traduções deste autor em Portugal durante o século XIX. Estes resultados são corroborados por Gabriela Gândara Terenas, que analisou a presença da literatura e da cultura britânicas na imprensa periódica portuguesa entre 1865 e $1890,{ }^{16}$ e também por Maria Zulmira Castanheira, que fez o levantamento dessas referências no período compreendido entre 1836 e $1865 .{ }^{17}$ No vasto conjunto de periódicos oitocentistas estudados pelas autoras não foram encontradas quaisquer traduções livres, "versões" ou "imitações" de Keats. Também não existem em volumes publicados nesse século, sendo o poeta apenas parcialmente traduzido para o português europeu por Rodrigo Solano (1879-1910) na sua única obra, Fumo, editada postumamente em $1915 .^{18}$

Relativamente a menções a Keats e à sua obra na imprensa periódica portuguesa do século XIX, a primeira (e aquela que parece ser a única) aparenta ter surgido numa edição de 1883 do periódico $A M u$ lher, dedicado ao público leitor feminino. Segundo Gabriela Gândara Terenas, ${ }^{19} \mathrm{o}$ artigo, da autoria do articulista francês Léo Quesnel e traduzido para português por uma entidade anónima, é dedicado à poesia de Elizabeth Browning (1806-1861), sendo que nele o autor refere Keats e Coleridge, entre outros, como influências literárias desta poetisa inglesa da era vitoriana:

\footnotetext{
14. Cf. Rodrigues, 1992.

15. Cf. Lousada, 1998.

16. Cf. Terenas, 2004.

17. Cf. Castanheira, 2005.

18. Nesta obra encontra-se uma única tradução de Keats, apresentada ao leitor como uma "imitação".

19. Cf. Terenas, 2004, vol. II: 984 .
} 
(...) Leigh-Hunt, que lhe chamava a irmã de Tennyson, mais razão teria chamando-lhe uma irmã de Keats. (...) como Keats, o seu génio poder-se-hia dizer que está impregnado do genio da antiguidade grega, não comprehendendo coisa alguma superior aos deuses. (1883: 117 e 147)

De facto, trata-se de uma referência pouco satisfatória, e de quase nada serviria a um leitor que, muito provavelmente, desconhecia por completo a poesia de Keats. Ignoram-se as tiragens totais de cada volume do periódico, ${ }^{20}$ mas, com apenas dois anos de publicação (entre 1883 e 1885), pode presumir-se que a sua popularidade não tenha sido particularmente elevada entre o público leitor.

Já num texto da autoria de Eça de Queirós, intitulado "O Francesismo", datado de 1887, é também possível encontrar-se uma brevíssima referência a certos autores consagrados do romantismo inglês. No meio de uma crítica ao estatuto primordial que a cultura e a língua francesas detêm no sistema literário do Portugal finissecular, Eça menciona o quão excepcionais são os poetas românticos ingleses, especialmente quando comparados com os seus equivalentes franceses: "Nunca a França teve um só poeta comparável aos poetas ingleses, a Burns, a Shelley, a Byron, a Keats, homens de emoção e de paixão, tão poéticos como os seus poemas". (1984: 340) Embora Eça reconheça a importância destes poetas no campo literário, a verdade é que tanto Burns como Shelley e Keats passaram largamente despercebidos à maioria do público leitor português da época.

Ora, aparentemente, aqui se inicia e cessa a recepção de Keats no Portugal do século XIX. Para Álvaro Manuel Machado e Daniel-Henri Pageaux, os dois casos acima mencionados seriam respeitantes ao sexto nível da escala de recepção, ${ }^{21}$ no qual se caracteriza a imagem cultural de um determinado autor estrangeiro através de outros testemunhos relevantes: não existem adaptações nem traduções; não se encontram leituras críticas da obra do autor na imprensa; não há qualquer difusão editorial da sua produção literária; não existem comparações com outros meios artísticos; e não se encontraram referências a Keats em narrativas de viagem pelo país. Estas

20. Cf. Roldão, 2013: 4.

21. Cf. Machado e Pageaux, 1988: 89-91. 
múltiplas ausências culturais invalidam a sua presença em qualquer outra posição esquemática da referida escala, embora a literatura e a cultura inglesas já tivessem sido anteriormente recebidas de forma positiva em Portugal. Restam, portanto, apenas dois brevíssimos testemunhos, favoráveis ao autor em apreço: o primeiro publicado num periódico com um público-alvo limitado, e o segundo proveniente de um dos mais consagrados e proeminentes escritores portugueses. Este último, em particular, poderia ter incitado algumas mentes mais curiosas a uma investigação literária em pleno final de século, não fosse o facto de "O Francesismo" apenas ter sido publicado onze anos após a morte de Eça, já em inícios de Novecentos.

Keats e a maioria dos autores românticos ingleses, na verdade, apenas foram "descobertos" em Portugal, segundo Álvaro Manuel Machado, em inícios do século XX, por Fernando Pessoa e pela Geração do Orpheu, sendo o próprio Pessoa quem demonstrou maior capacidade para assimilar as influências destes poetas. Machado problematiza esta influência tardia dos mais consagrados românticos ingleses em Les Romantismes au Portugal, colocando a seguinte questão:

Pourquoi Fernando Pessoa "découvre" et diffuse au début du XXe siècle, en pleine période de rupture du mouvement moderniste de la revue Orpheu, des poètes du premier romantisme anglais jusque là pratiquement inconnus, ou tout au moins sans aucune influence sur les poètes romantiques portugais, comme Wordworth, Coleridge, Keats, Shelley? (1986: 12)

Pode, então, afirmar-se que a recepção literária de Keats no sistema cultural português não foi suficientemente marcante durante o século XIX para se categorizar como uma recepção propriamente dita. De facto, não houve uma reacção evidente do público leitor português aos textos, porque a leitura do poeta apenas poderia ter sido realizada por um grupo muito limitado de intelectuais versados na língua inglesa, dado que a poesia de Keats não chegou a ser traduzida para francês (nem para a maioria das restantes línguas europeias) até inícios de século $\mathrm{XX}^{22}$ invalidando uma eventual oportunidade para recepção via mediação. Relativamente ao sistema cultural francês do

22. Cf. Matthews, 2005: 10. 
século XIX, também aí se verificou um fraco interesse pela obra do autor, sendo o mito de Keats (e da sua trágica vida) o promotor de maior discussão entre os intelectuais gauleses de Oitocentos, no tocante ao poeta. A partir da segunda metade do século, contudo, começaram a surgir escassos estudos sobre a sua obra que não chegaram a Portugal, embora alguns deles estivessem presentes em periódicos de renome que constituíram fontes de importação de artigos para a imprensa periódica portuguesa por via da tradução, como por exemplo a Revue des Deux Mondes. No entanto, parece que a usual difusão decorrente destas duas formas de recepção não foi suficiente, dada a ausência de traduções da sua poesia, para permitir um reconhecimento do autor alargado ao público leitor em geral, sendo esse desinteresse generalizado pelo autor transposto para Portugal.

Assim, a fraca recepção inicial de Keats em Portugal terá sido um reflexo da sua diminuta recepção em França, à semelhança de vários outros autores ingleses. Enquanto Lord Byron e Walter Scott, os dois autores românticos ingleses mais traduzidos para português, foram muitíssimo apreciados em França e, consequentemente, em Portugal, os restantes românticos, hoje considerados autores canónicos, não receberam o mesmo tratamento, o que certamente influenciou a sua transposição para o país, que, então, se encontrava largamente dependente da mediação gaulesa. Outros poetas menores, como Thomas Moore, terão igualmente desfrutado de uma recepção positiva em ambos os sistemas literários. Tal dependência, que se estendeu até meados do século XX, terá sido fruto da posição central então ocupada por França dentro do polissistema europeu, face à posição periférica ocupada por Portugal e por tantos outros países que procuraram em França novidades literárias e culturais. Poder-se-á eventualmente afirmar que John Keats sofreu uma não-recepção em Portugal durante o século XIX, a par da sua não-tradução.

Esta completa ausência de Keats em Portugal terá cessado em meados do século XX, com um aumento substancial no número de traduções e textos ensaísticos sobre o autor e a sua obra. Segundo as pesquisas efectuadas para o presente estudo, contam-se sete autores que atentaram na tradução da poesia de John Keats desde os inícios do século XX: o já referido Rodrigo Solano, na sua colecção de poesia Fumo, editada postumamente em 1915; Jaime de Magalhães Lima (1859-1936), em 1929, para a edição $\mathrm{n}^{\circ} 12$ do segundo volume 
do periódico portuense Portucale; Fernando Guimarães (1928-), em 1960, numa obra intitulada Odes, e novamente em 1977, em Poesia Romântica Inglesa: Byron, Shelley, Keats; Jorge de Sena (1919-1978), em 1971, numa antologia poética por si traduzida, intitulada Poesia de 26 Séculos; Manuela Freire (1926-), que traduziu em 1981 os vários poemas de diferentes autores presentes na obra de Edith Holden, A Alegria de Viver com a Natureza: Diário de Edith Holden; Jorge Vilhena Mesquita (1960-), para a edição $\mathrm{n}^{\circ} 2$ do periódico de poesia e tradução Diversos; e António Simões (1934-), em 2002, na Antologia de Poesia Anglo-Americana, traduzida pela sua mão. Quatro das obras aqui listadas consistem em antologias poéticas: Poesia Romântica Inglesa incorpora traduções de poemas escolhidos de Lord Byron, Percy Bysshe Shelley e John Keats, encontrando-se na sua terceira edição; Poesia de 26 Séculos conta também com três edições até à data, contendo traduções de vários poetas das mais diversas nacionalidades, produzidas ao longo dos tempos, começando em Safo e terminando com Nietzsche; A Alegria de Viver com a Natureza, embora não seja uma antologia per se, apresenta a tradução de poemas de vários poetas ingleses famosos, seleccionados consoante o critério da autora vitoriana, tendo gerado apenas uma edição; e Antologia de Poesia Anglo-Americana apresenta traduções poéticas de autores de língua inglesa, desde Geoffrey Chaucer até Dylan Thomas, mantendo-se, por ora, na sua primeira edição. Deve sublinhar-se que as antologias de Fernando Guimarães e de António Simões são as únicas obras presentemente em circulação em Portugal com traduções portuguesas da poesia do autor romântico em apreço.

Assim, podem actualmente totalizar-se as traduções de "Answer to a Sonnet by J. H. Reynolds, ending - 'Dark eyes are dearer far/ Than those that mock the hyacinthine bell.'" (comummente conhecido como "Blue Eyes") (da autoria de Rodrigo Solano), excertos do poema "Endymion" (da autoria de Jaime de Magalhães Lima e Fernando Guimarães), "Ode on a Grecian Urn" (traduções de Fernando Guimarães, Jorge de Sena e António Simões), "Written in Disgust of Vulgar Superstition" (de Jorge de Sena), "To Autumn" (traduções de Fernando Guimarães, Maria Manuela Freire e António Simões), "Ode to a Nightingale" (por Fernando Guimarães e Jorge Vilhena Mesquita), "Ode on Indolence", "Ode on Melancholy", "After Dark Vapours Have Oppress'd our Plains", "This Living Hand", "To One Who Has 
Long Been in City Pent" e excertos do poema "Isabella or the Pot of Basil" (da autoria de Fernando Guimarães). É evidente o valor que Fernando Guimarães, premiado poeta e ensaísta, detém na tradução deste autor para português, dado que a larga maioria das traduções existentes até à data são da sua autoria. As suas escolhas revelam não só atenção dada aos textos de Keats considerados canónicos, uma vez que traduz as odes mais importantes, mas também um certo gosto pessoal, pois opta por traduzir também poemas menos consagrados da obra keatsiana, como, por exemplo, "To One Who Has Long Been in City Pent" ou "After Dark Vapours Have Oppress'd Our Plains".

Não obstante as traduções existentes, subsiste ainda uma lacuna na transposição da obra de Keats para português europeu. Poemas célebres como "Sleep and Poetry", "When I Have Fears That I May Cease Be", "La Belle Damme sans Merci", "The Eve of St. Agnes" e "Bright Star" não foram ainda vertidos, incindindo os tradutores principalmente nas odes do poeta. Para um autor considerado canónico no âmbito da Literatura Inglesa, o número de traduções afigura-se um tanto escasso.

Quanto à famosa correspondência de Keats com a família e os amigos, contam-se duas traduções produzidas em Portugal: Salvato Menezes (1949-), reconhecido tradutor e Professor Universitário, traduziu, em 1984, as cartas "To Benjamin Bailey", de 22 de Novembro de 1817, e "To J. H. Reynolds", datada de 3 de Maio de 1818, para a antologia coordenada por Álvaro Pina (1942-), Posições Românticas na Literatura Inglesa, onde se encontram reunidos textos traduzidos da autoria de vários escritores ingleses.

Relativamente a textos ensaísticos sobre o poeta e a sua obra, é possível encontrar-se um número razoável de artigos, dissertações de mestrado e teses de doutoramento produzidos em Portugal. Curiosamente, a larga maioria destes ensaios consiste em textos de uma natureza comparativista, sendo que vários incidem sobre a influência concreta de Keats sobre determinados poetas portugueses do século XX. 


\section{Obras Citadas}

\section{I) Fontes Primárias}

Byron, Lord, John Keats e Percy Bysshe Shelley. Poesia Romântica Inglesa. 3. ${ }^{\mathrm{a}}$ edição, revista e aumentada. Trad. Fernando Guimarães. Lisboa: Relógio D’Água, 2010.

Keats, John. "Ode a um Rouxinol". Trad. Jorge Vilhena Mesquita. Diversos Revista Semestral de Poesia e Tradução, no 2 (Primavera/Verão) (1997): 15-17.

---. Odes. Trad. Fernando Guimarães. Porto: Livraria Sousa e Almeida, 1960.

Holden, Edith. A Alegria de Viver Com a Natureza: Diário. Trad. Manuela Freire e António José Massano. Barcelona: Blume, 1981.

Lima, Jaime de Magalhães. "Glosas Bárbaras. II Arca da Aliança”. Portucale, vol. II, $\mathrm{n}^{\circ} 12$ (1929): 405-7.

Sena, Jorge de. (comp. e trad.) Poesia de 26 Séculos. Volumes I e II. Porto: Editorial Inova Limitada, 1971.

Simões, António (comp. e trad.). Antologia de Poesia Anglo-Americana: De Chaucer a Dylan Thomas. Porto: Campo Das Letras, 2002.

Solano, Rodrigo. Fumo (Livro dum Poeta Morto). Penafiel: Câmara Municipal de Penafiel, 2010.

\section{II) Fontes Secundárias}

Braga, Teófilo. História do Romantismo em Portugal. Vols. I e II. Braga: Edições Vercial, 2014.

Castanheira, Maria Zulmira. A Grã-Bretanha na Imprensa Periódica de Romantismo Português: Imagens Polimórficas. Volumes I e II. Lisboa: Faculdade de Ciências Sociais e Humanas da Universidade Nova de Lisboa, 2005.

---. "A Literatura Inglesa na Imprensa Periódica Portuguesa do Romantismo". Revista de Estudos Anglo-Portugueses, 17 (2008): 127-254.

Dias, Miguel. Sobre a (Não-) Tradução de John Keats: Séculos XIX-XX. Dissertação de Mestrado em Tradução (Área de Especialização em Inglês). Lisboa: Universidade Nova da Lisboa, 2017.

Even-Zohar, Itamar. "Polysystem Studies". Poetics Today, vol. 11, no 1 (1990). $1-252$.

Flor, João Almeida. "Byron, Lamartine e Alcipe num Soneto Português (1884)". Anglo-Saxónica: Revista do Centro de Estudos Anglísticos, $2^{\text {a }}$ série, $\mathrm{n}^{\mathrm{o}} 27$ (2009): 143-156.

Lousada, Isabel Maria da Cruz. Para o Estabelecimento de uma Bibliografia Britânica em Português (1554-1900). Lisboa: Universidade Nova de Lisboa, 1998.

Machado, Álvaro Manuel e Daniel-Henri Pageaux. Da Literatura Comparada à Teoria da Literatura. Lisboa: Edições 70, 1988. 


\section{ESTUDOS/ESSAYS}

Machado, Álvaro Manuel. Les Romantismes au Portugal: Modèles Étrangères et Orientations Nationales. Paris: Fondation Calouste Gulbenkian, 1986.

Matthews, G. M. (ed.) John Keats, the Critical Heritage. London/New York: Routledge, 2005.

Pina, Álvaro (coord.) Posições Românticas na Literatura Inglesa. Antologia. Lisboa: Livros Horizonte, 1984.

Pires, Maria Laura Bettencourt. Walter Scott e o Romantismo Português. Lisboa: Faculdade de Ciências Sociais e Humanas, 1979.

Queirós, Eça de. Últimas Páginas. Lisboa: Publicações Europa-América, 1984.

Quesnel, Léo. "Os Poetas Modernos da Inglaterra. Elisabeth Barrett Browning". A Mulher (Lisboa, 1883-1885), $1^{\circ}$ ano, $\mathrm{n}^{\circ} 15$, [s.d.] [1883?]: 117 e $\mathrm{n}^{\circ}$ 19, [s.d.] [1883?]: 147. [tradução anónima]

Roldão, M. Helena. "A Mulher". Hemeroteca Digital de Lisboa. 06 de Março 2013. Web. 04 de Novembro 2016. <hemerotecadigital.cm-lisboa.pt/FichasHistoricas/AMulher.pdf>.

Rodrigues, A. A. Gonçalves. A Tradução em Portugal: Tentativa de Resenha Cronológica das Traduções em Língua Portuguesa Excluindo o Brasil de 1495 a 1950. Vol. I - V. Lisboa: Imprensa Nacional Casa da Moeda, 1992.

Silva, Jorge Bastos da. "Problemática da Tradução em Portugal no Século XIX". Tradução e Cultura Literária. Ensaios Sobre a Presença de Autores Estrangeiros em Portugal. Porto: Edições Afrontamento, 2014. 11-38.

Sousa, Maria Leonor Machado de. "Tempting Demon': the Portuguese Byron". The Reception of Byron in Europe. Volume I: Southern Europe, France and Romania. Ed. Richard Cardwell. London/New York: Thoemmes Continuum, 2004. 164-187.

Terenas, Gabriela Gândara. Diagnoses Especulares: Imagens da Grã-Bretanha na Imprensa Periódica Portuguesa (1865-1890). Volumes I e II. Lisboa: Faculdade de Ciências Sociais e Humanas da Universidade Nova de Lisboa, 2004.

---. "French Mediation, the Construction of British Images and the Portuguese Press". Beyond Binarisms. Crossing and Contaminations: Studies in Comparative Literature. Ed. Pina Coco e Eduardo F. Coutinho. Rio de Janeiro: Aeroplano Editora, 2009. 161-170. 